This item was submitted to Loughborough's Research Repository by the author.

Items in Figshare are protected by copyright, with all rights reserved, unless otherwise indicated.

\title{
The mundane experience of everyday calorie trackers: Beyond the metaphor of Quantified Self
}

PLEASE CITE THE PUBLISHED VERSION

https://doi.org/10.1177/1461444817698478

\section{PUBLISHER}

(C) The Authors. Published by SAGE Publications (UK and US)

\section{VERSION}

AM (Accepted Manuscript)

\section{PUBLISHER STATEMENT}

This work is made available according to the conditions of the Creative Commons Attribution-NonCommercialNoDerivatives 4.0 International (CC BY-NC-ND 4.0) licence. Full details of this licence are available at: https://creativecommons.org/licenses/by-nc-nd/4.0/

\section{LICENCE}

CC BY-NC-ND 4.0

\section{REPOSITORY RECORD}

Didziokaite, Gabija, Paula Saukko, and Christian Greiffenhagen. 2017. "The Mundane Experience of Everyday Calorie Trackers: Beyond the Metaphor of Quantified Self”. figshare. https://hdl.handle.net/2134/24405. 


\title{
The mundane experience of everyday calorie trackers: Beyond the metaphor of Quantified Self
}

\author{
Gabija Didžiokaite (Loughborough University, UK), \\ Paula M. Saukko (Loughborough University, UK), \& \\ Christian Greiffenhagen (The Chinese University of Hong Kong, Hong Kong) ${ }^{1}$
}

\section{Abstract}

In this article, we build on the work of Ruckenstein and Pantzar (2015), who have demonstrated how our understanding of self-tracking has been influenced by the metaphor of the Quantified Self (QS). To complicate this very selective picture of selftracking, we shift the focus in understanding self-tracking from members of the QS community to the experiences of 'ordinary man and woman' (Bakardjieva and Smith, 2001). We, therefore, interviewed 'everyday calorie trackers', people who had themselves started using MyFitnessPal calorie counting app but were not part of any tracking community. Our analysis identifies three main themes - goals, use and effect - which highlight the mundane side of self-tracking, where people pursuing everyday, limited goals engage in basic self-tracking and achieve temporary changes. These experiences contrast with the account of self-tracking in terms of long-term, experimental analysis of data on the self or 'biohacking,' which dominates the QS metaphor in the academic literature.

\footnotetext{
1 The second and third author contributed equally to the article, the order of names is alternated in different publications.
}

Didžiokaite, G., Saukko, P., \& Greiffenhagen, C. (forthcoming). The mundane experience of everyday calorie trackers: Beyond the metaphor of Quantified Self. Forthcoming in New Media \& Society. 
'The quantified self (QS) is any individual engaged in the self-tracking of any kind of biological, physical, behavioral, or environmental information.' (Swan, 2013: 85)

'The term "quantified self" is now frequently used not only in relation to members of the Quantified Self movement itself, but more generally to refer to the practices of self-tracking or lifelogging.' (Lupton, 2013b: 26)

'As a metaphor, the [quantified self] does not only define a new numerical self but also promotes a framework within which such a self operates. From this perspective, Wired is using the notion of the QS to capture certain interests and desires for the future, while ignoring and downplaying others.' (Ruckenstein and Pantzar, 2015: 2)

\section{From Self-Tracking to the Quantified Self Metaphor}

People have long been keeping track of their food consumption, weight and performance changes. However, more detailed and nuanced ways of self-tracking have become possible through the emergence of new and increasingly more intelligent devices, which include wristband pedometers, sleep trackers, fertility trackers and many more. Every year more technologies and apps that help track various aspects of health and bodily performance are released to the market (Statista, 2015) and now wristband pedometers that synchronise with your mobile phone can be found in supermarkets. This demonstrates that self-

Didžiokaite, G., Saukko, P., \& Greiffenhagen, C. (forthcoming). The mundane experience of everyday calorie trackers: Beyond the metaphor of Quantified Self. Forthcoming in New Media \& Society. 
tracking, once the domain of a small group of enthusiasts, has become popular among the wider population.

Self-tracking is also at the centre of the Quantified Self (QS) movement, which started in San Francisco but has spread world-wide. QS is based around the idea of 'self-knowledge through numbers', i.e. has the aim to use new self-tracking technologies to quantify as many aspects of your life as possible (number of steps walked, calories consumed, hours slept, stress levels experienced, and so on) and to use this new knowledge to change, and improve, your life. Members of the QS community share their experiences on and off-line and often have taken self-tracking to the next level by inventing new technologies or thinking of innovative ways to use existing technologies (Choe et al., 2014; Li et al., 2010; Wolf, 2010).

The practices and experiences of the QS community are often evoked when self-tracking is discussed in the media (Cha, 2015; Weintraub, 2013). In fact, QS has often become conflated with self-tracking in general (Lupton, 2013b: 26), which has not always been welcomed by the QS community itself (Neff and Nafus, 2015). According to Ruckenstein and Panztar (2015), QS has become an 'ontological' metaphor for self-tracking, it is used to categorise and identify key aspects of this new phenomenon (Lakoff and Johnson, 1980). As scholars in science and technology studies (STS) have shown, metaphors of new technologies are powerful tools, since due to their ability to resonate in different contexts they can offer common ground for discussion (Cohen and Blavin, 2002; Hellsten, 2003;

Didžiokaite, G., Saukko, P., \& Greiffenhagen, C. (forthcoming). The mundane experience of everyday calorie trackers: Beyond the metaphor of Quantified Self. Forthcoming in New Media \& Society. 
Wyatt, 2004). However, metaphors are also limiting, since they only reflect a particular understanding of technologies (Hellsten, 2003). For example, discussions of new technologies often use metaphors that evoke 'revolutionary' changes, like computer or information revolution' (Winner 1986 in Wyatt, 2004: 253). Ruckenstein and Pantzar (2015: 2) also note that QS is associated with 'disjuncture' in articles published in the Wired magazine, which employs the metaphor to 'model' an emerging data driven market, full of promise.

Ruckenstein and Pantzar (2015) identify four aspects at the heart of the QS metaphor, namely the idea of transparency in the quantified world, the wish of optimizing health performance, the possibilities of feedback loops for behaviour change, and the idea of biohacking discoveries. Through a critical analysis of the arguments in the Wired articles, Ruckenstein and Pantzar demonstrate how the metaphor misleads us in our understanding of the everyday practices of self-tracking or 'what the sharing, analyzing, and discussing of personal data promotes in the everyday' (2015: 2).

To complicate the very selective picture of self-tracking, we shift the focus in understanding self-tracking from members of the QS community to people who engage in self-tracking, but without being part of any wider 'movement'. Our work follows in the footsteps of earlier scholarship on internet use, which has emphasised the importance of studying users, who engage with the technology in a limited manner or do not use it (e.g., Henwood et al., 2003; Wyatt, 2003). These scholars have warned about the dangers of

Didžiokaite, G., Saukko, P., \& Greiffenhagen, C. (forthcoming). The mundane experience of everyday calorie trackers: Beyond the metaphor of Quantified Self. Forthcoming in New Media \& Society. 
focusing on keen users, such those participating in peer-to-peer online health groups, and ignoring users who confine their use of technologies or reject them. Neglect of less avid user groups risks buttressing dominant discourses, such as the idea that Internet leads to patient empowerment.

For example Henwood et al. (2003) observed that middle-aged women, who were making decisions about taking hormone replacement therapy (HRT), used the Internet together with many other sources, such as doctors, family and books, to find information. Many also did not consult the Internet, sometimes because they did not want to take the responsibility or burden. Similarly, Nettleton, Burrows and O'Malley (2005) noted that parents of children with chronic conditions presented themselves as 'sensible' users of the Internet, accessing 'reliable' biomedical information, which ran counter to arguments celebrating Internet as fostering lay expertise.

Whilst Internet use was imagined as revolutionising health in the early noughties, selftracking is currently associated with similar extraordinary expectations in the discussions on QS. Thus, to widen our understanding of self-tracking we studied, what Bakardjieva and Smith (2001: 68) - drawing on De Certeau (1984) and Schutz \& Luckmann (1973) have called 'ordinary man and woman' and what we, in our case, refer to as 'everyday selftrackers': people who have downloaded or purchased an app (in our case, MyFitnessPal) and are using it on their own without belonging to any movement. Their experiences of everyday calorie trackers: Beyond the metaphor of Quantified Self. Forthcoming in New Media \& Society. 
reveal a rather different picture of self-tracking than the one offered by the QS metaphor (see 'Methods' below).

We identified three key themes related to self-tracking in our interview material, which contrast with the way in which self-tracking is typically talked about in the literature: goals, use, and effects. The literature that we reviewed includes visionary or conceptual work on Quantified Self as well as studies on the practices of actual members of the QS community (QSers). The differences between our interview material and the QS metaphor are synthesised in Table 1.

In the next section, we will discuss the left side of the table through an analytic literature review. After describing our methods of data collection, the 'Findings' section will describe the right side of the table.

Didžiokaite, G., Saukko, P., \& Greiffenhagen, C. (forthcoming). The mundane experience of everyday calorie trackers: Beyond the metaphor of Quantified Self. Forthcoming in New Media \& Society. 
Table 1 Comparison of QS metaphor and everyday calorie trackers

\begin{tabular}{|c|c|c|}
\hline & QUANTIFIED SELF METAPHOR & $\begin{array}{l}\text { EVERYDAY } \\
\text { TRACKERS }\end{array}$ \\
\hline GOALS & $\begin{array}{l}\text { - 'Self-knowledge through numbers' } \\
\text { (Ruckenstein, 2015; Schüll, 2016; } \\
\text { Swan, 2012) } \\
\text { - Self-optimization (Choe et al., 2014: } \\
\text { 1147; Lupton, 2016; Ruckenstein and } \\
\text { Pantzar, 2015; Sharon and } \\
\text { Zandbergen, 2016; Whooley et al., } \\
\text { 2014: 154) }\end{array}$ & $\begin{array}{l}\text { - Lose (sometimes maintain) } \\
\text { weight } \\
\text { - Mainly to look better and } \\
\text { sometimes to be healthier }\end{array}$ \\
\hline USE & $\begin{array}{l}\text { - Critical approach to data, norms and } \\
\text { suggestions (Lupton, 2013b; Nafus } \\
\text { and Sherman, 2014; Neff and Nafus, } \\
\text { 2015; Ruckenstein and Pantzar, 2015; } \\
\text { Sharon and Zandbergen, 2016) } \\
\text { - Hacker tinkering with the hardware, } \\
\text { software and analytical categories set } \\
\text { by tracking tools (Choe et al., 2014; } \\
\text { Ruckenstein and Pantzar, 2015; } \\
\text { Sharon and Zandbergen, 2016; } \\
\text { Whooley et al., 2014) } \\
\text { - 'Lay scientist, exploring retrospective } \\
\text { data for trends and patterns to } \\
\text { calculate optimal choices (Choe et al., } \\
\text { 2014; Lee, 2014; Ruckenstein and } \\
\text { Pantzar, 2015; Whooley et al., 2014) }\end{array}$ & $\begin{array}{l}\text { - Trust in data as expert } \\
\text { knowledge } \\
\text { - Using basic functions, rarely } \\
\text { exploring advanced features of } \\
\text { the technology }\end{array}$ \\
\hline EFFECTS & $\begin{array}{l}\text { - Using data to create self and the } \\
\text { future (Lupton, 2013a, 2013b, 2016; } \\
\text { Sharon and Zandbergen, 2016; Swan, } \\
\text { 2013) } \\
\text { - Self-quantification as a way of living } \\
\text { (Choe et al., 2014; Ruckenstein and } \\
\text { Pantzar, 2015; Schüll, 2016) }\end{array}$ & $\begin{array}{l}\text { - Perceiving foods as calories } \\
\text { and becoming more aware of } \\
\text { eating habits } \\
\text { - Temporary use and effects, } \\
\text { calorie counting dropped } \\
\text { when app not used }\end{array}$ \\
\hline
\end{tabular}

Didžiokaite, G., Saukko, P., \& Greiffenhagen, C. (forthcoming). The mundane experience of everyday calorie trackers: Beyond the metaphor of Quantified Self. Forthcoming in New Media \& Society. 
QS as metaphor

Goals

The literature on QS relates the goals of self-tracking to the pursuit of transparency and selfoptimization. These two principles come together in the QS slogan 'self-knowledge through numbers'.

The idea of transparency is predicated on the idea that people are 'data-hungry and eager to take advantage of the growing amounts of data generated by sensors, satellite images and search engines' (Ruckenstein and Pantzar, 2015: 7). These new forms data can be harvested through self-tracking and used to make the world and the self increasingly more transparent. For example, Swan states that the reason for an individual to get involved in quantified self projects was 'to understand his or her own patterns and baseline measures and obtain early warnings' (Swan, 2012: 95). Schüll (2016: 9) identifies a similar sentiment in statements of the wearable tech industry, which promise that these products 'help fill in the blind spots and take the guesswork out of everyday living.'

The QS quest for minutiae data about all facets of life is driven by the wish for optimisation. Data is perceived as enabling improvement of diverse aspects one's life and body. Lupton (2016: 64) notes that self-tracking is portrayed as a pursuit for 'an optimal human being', while studies of QS members (QSers) show that they want to 'improve health, maximize work performance, and find new life experiences through self-tracking' (Choe et al., 2014: 1147) and are driven by 'self-improvement and curiosity' (Whooley et

Didžiokaite, G., Saukko, P., \& Greiffenhagen, C. (forthcoming). The mundane experience of everyday calorie trackers: Beyond the metaphor of Quantified Self. Forthcoming in New Media \& Society. 
al., 2014: 154). Sharon and Zandbergen (2016: 2) point out that literature, which is critical of QSers, also depicts them as driven 'by a desire to control and optimize the overwhelming complexity and uncertainty of life.'

In contrast with these goals of obtaining vast quantities of data to render life and performance transparent and knowable, our participants had a more specific, and limited, goal, mainly losing weight. They wanted to lose weight to look better, and sometimes to be healthier. Whilst losing weight is a type of self-improvement, it is more modest, and more traditional than the expansive goal of 'optimising' different facets of the body, self and life. Hence, while the QS metaphor in the literature makes self-trackers to stand for a 'datadriven health revolution' (Ruckenstein and Pantzar, 2015: 8), we found our participants to be driven by more specific, modest, and less novel mundane goals.

Use

The discussions on QS give a picture of highly creative, critical, and innovative use. This is encapsulated in the notion of 'biohacking' (Ruckenstein and Pantzar, 2015), whereby selftrackers experiment with their data and bodies to find their individual indicators of wellbeing. Biohacking presents self-trackers as actively questioning the data provided by self-tracking devices in order to find the purpose of personal data and to 'seek to control their "data selves" (Lupton, 2013b: 29). QS can be seen as shifting attention from the normal curve to 'what is normal for me' (Neff and Nafus, 2015).

Didžiokaite, G., Saukko, P., \& Greiffenhagen, C. (forthcoming). The mundane experience of everyday calorie trackers: Beyond the metaphor of Quantified Self. Forthcoming in New Media \& Society. 
The image of a hacker emphasises a sense of creativity and personalisation (Ruckenstein and Pantzar, 2015: 10). QSers do not just (passively) use self-tracking technologies, they adapt, change, tweak, and alter them. The image of the user, emerging from studies of QS, is one of a creator who 'built their own tools' even if 'numerous commercial self-tracking tools are available' (Choe et al., 2014: 1149) or 'wrote software programs that could extract data and integrate it into a representation they were happy with' (Whooley et al., 2014: 155).

This critical way of studying yourself has led to a view of self-trackers as lay, or $n=1$ (Nafus and Sherman, 2014; Sharon and Zandbergen, 2016), scientists. According to this view, self-trackers explore their data, experiment with their bodies (Lupton, 2013b) and 'consider and address issues related to the scientific soundness of [their] projects' (Swan, 2013: 92). Self-trackers are thus not just seen as creative, they are also portrayed as highly critical.

Our participants, rather than 'hacking' the app, typically relied its basic functions. Many of them were not aware of, or interested in, using the more advanced features of the technology, let alone going 'beyond' them. Our participants did not think about new ways of using the collected data. In fact, they rarely even looked at the historical data to identify trends or learn about their body. Instead, they tracked prospectively, looking at calories for the day or at app's prognosis of weight loss. Furthermore, rather than adopting a 'critical' or 'sceptical' attitude, our participants basically trusted the data provided by the app. In

Didžiokaite, G., Saukko, P., \& Greiffenhagen, C. (forthcoming). The mundane experience of everyday calorie trackers: Beyond the metaphor of Quantified Self. Forthcoming in New Media \& Society. 
other words, they did not seek further data or compare different data on e.g. embodied experiences.

\section{Effects}

At the heart of the QS metaphor is the idea that self-tracking contributes to the creation of a new kind of self, the 'quantified self' (Swan, 2013: 95). The use of, and experimentation with, these new forms of data leads not just to a new self, but a 'better' self. The new knowledge brought by self-tracking is contributing to the self-creation. Tracking is presented as 'means of enabling the constant creation of the self' (Swan, 2013: 95), seen to happen through the interpretation of the quantitative data, or the 'qualitative' part of QS (Lupton, 2013b: 29, 2016: 112). This interpretation, together with experimentation is seen to "transform the quantified self into an improved "higher quality" self (Swan, 2013: 93), who has a better understanding of itself than the ordinary one. The data and its interpretation are often highlighted as serving an important role in the 'continuous process of identity construction' (Sharon and Zandbergen, 2016: 11). Hence, Lupton (2013a: 397) argues that 'self-tracking represents the apotheosis of self-reflexivity' geared towards making 'choices about future behaviours.'

Self-tracking is seen as not just leading to the creation of a new self, but to a whole new way of living - 'the data-driven life' as put by one of the QS community founders Gary Wolf (2010). Self-tracking, and gathering quantitative information about yourself, is thus not just a method of data collection, but 'an approach to better life' (Choe et al., 2014:

Didžiokaite, G., Saukko, P., \& Greiffenhagen, C. (forthcoming). The mundane experience of everyday calorie trackers: Beyond the metaphor of Quantified Self. Forthcoming in New Media \& Society. 
1147). In fact, it becomes 'a mission in life' (Ruckenstein and Pantzar, 2015: 7). This mission is to gain as much knowledge about as many aspects of your life so that you improve your life in various ways. As Schüll puts it: 'we are invited to view ourselves as longitudinal databases constantly accruing new content' (2016: 9).

Our participants did not perceive the data they tracked as contributing to the creation of a new self or identity. They did start to look at food differently and used their new knowledge about the calorie content of food items to restructure their meals, but this did not constitute the beginnings of a new, 'data-driven', way of life. Furthermore, for our participants self-tracking was not a long-term, or life-encompassing, activity. Self-tracking was something that they engaged in on a temporary basis when they needed to lose weight. Calorie tracking with the app was typically stopped after a while, and our participants would return to their usual eating habits.

The depiction of self-tracking in terms of QS metaphor has not been unquestioned and there have been a few studies that have provided insights into the practices of more ordinary self-trackers that go against the grain of the metaphor. For example, Rooksby et al. (2014) interviewed people, who self-tracked physical activity. Their participants often used apps for short periods to help achieve long-term goals, perceived tracking as 'prospective' (Rooksby et al., 2014: 1171) and were not interested in reviewing the collected data. Similarly, Niva (2015) interviewed women using online weight-loss programs. Like our participants, these women did not question the usefulness of calories

Didžiokaite, G., Saukko, P., \& Greiffenhagen, C. (forthcoming). The mundane experience of everyday calorie trackers: Beyond the metaphor of Quantified Self. Forthcoming in New Media \& Society. 
or the science behind the program. Though they were keen and expected calorie counting to become their lifestyle, many women eventually lost the motivation to continue, showing that self-tracking does not necessarily become 'a mission in life.' Our findings below contribute to creating a more inclusive and nuanced notion of self-tracking than the one offered by the QS metaphor.

\section{Methods}

Everyday self-trackers can be difficult to recruit, as tracking is largely an individual and sometimes private practice. We deliberately did not want to study people from QS or other self-tracking communities to garner the perspectives of 'ordinary man and woman' who are not involved in design and development of technology (Bakardjieva and Smith, 2001: 68). We therefore initially got in touch with some of the local gyms in the UK East Midlands and talked to personal trainers working there. We also posted recruitment ads on local fitness Facebook groups, on a participant recruitment website (callforparticipants.com), and in the bulletin board for local university staff and students. The only criterion for participation was the previous or present use of MyFitnessPal.

After obtaining ethical clearance from our University, we recruited 31 participants, all of whom gave written informed consent. Most of our participants used MFP for dieting, some of our participants used the app mainly to improve fitness or sport performance and a few were personal trainers, who also used the app in their work. Our 31 participants consisted of 12 men and 19 women. They were mainly in their early midlife, ranging from

Didžiokaite, G., Saukko, P., \& Greiffenhagen, C. (forthcoming). The mundane experience of everyday calorie trackers: Beyond the metaphor of Quantified Self. Forthcoming in New Media \& Society. 
22 to 53 years of age, with the average age being 37 . To ensure participants' anonymity we use pseudonyms.

The interviews were semi-structured. Participants were asked to tell their story of using MyFitnessPal, to talk about their engagement with the app and to evaluate it. In addition to interviews, participants were also asked to provide a two-week extract of the food and exercise diary from MyFitnessPal. This was not compulsory and resulted in 16 extracts.

The first author conducted the interviews in 2015 either face to face $(n=28)$ or through Skype video calls $(n=3)$. The interviews were audio recorded and transcribed by the interviewer soon after they took place, which allowed improving questions as the research progressed. The thematic analysis was done with qualitative analysis software NVivo 10; starting with initial coding and the constant comparative method (Glaser and Strauss, 1967), while still collecting data, and when data collection was finished moving to focused coding. Employing this approach helped to determine the themes that had 'the most analytic sense' (Charmaz, 2006: 57) for the unravelling of collected data. Emerging themes were discussed or inter-rater checked (Denzin, 1978) between the three authors against the interview material.

We were struck by the mundane or ordinary way in which our participants used MyFitnessPal, which was often radically different from the way in which self-tracking had been portrayed in the academic literature. When further interrogating the material, we

Didžiokaite, G., Saukko, P., \& Greiffenhagen, C. (forthcoming). The mundane experience of everyday calorie trackers: Beyond the metaphor of Quantified Self. Forthcoming in New Media \& Society. 
identified the three aforementioned subthemes that related to the ordinariness of the participants' experiences: goals, practices of use and effects.

\section{Findings}

\section{Ordinary goals}

When asked to tell their story behind MyFitnessPal use, participants would usually mention that they were self-tracking to achieve a specific weight goal, mainly weight loss. Gemma, a sound engineer in her late twenties, was typical in this regard since she wanted 'just to track, track mostly food intake for trying to lose a bit of weight [laughs].' Similarly, Julie, a graphic designer in her twenties, wanted 'to lose weight, cause [I have] gone out of shape and obviously wasn't eating the right stuff.'

The reasons for wanting to lose weight varied. Many wanted simply to look and feel better. For example, Anamaria, a postgraduate student from Romania, stated:

I wasn't happy with weight, especially because I was eating a lot of sweets and not working out, I started having like huge sort of, like a doughnut ring or something [around my stomach], [...] And the clothes sort of didn't fit very well, they were like tighter.

Some users aimed for a one-off, figure-changing weight-loss, like Serge, a sound recordist in his forties, who was preparing for his wedding and wanted 'to lose a lot of weight, [to] look good at the wedding pictures.' Others used MyFitnessPal occasionally when they felt 
like they needed to lose a few kilograms. Sometimes this was done in preparation for a holiday or celebration, as explained by Justine, a 36-year-old project manager, who used MyFitnessPal for 'those kinds of holidays, birthdays, uh gonna be in a bikini, erm... on holiday with friends, don't want to show myself up type of thing.' Thus, similarly to selftrackers in Cordeiro, Epstein, et al. (2015) and Rooksby et al. (2014), MyFitnessPal users were usually self-tracking for a short-term and specific goal. These kinds of goals stand in contrast to the expansive and continuous goal of making self and life transparent and knowable through numbers, as crystallised in the QS tagline - 'self-knowledge through numbers.'

Sometimes the reasons for wanting to lose weight were related to wanting to look better and some health concern. Georgina, a gardener in her forties, who had counted calories since her twenties whenever she wanted to lose some weight, explicitly mentioned these two reasons:

It's a combination of things, I've got full hip replacement and femur replacement [...] So I keep my weight down, primarily because of my false hip and femur. And secondary would be image related, you know I like putting my skinny jeans on, and trying to keep, outside work, looking good, looking ok, going out and thinking - yeah, I'm happy with myself tonight.

Didžiokaite, G., Saukko, P., \& Greiffenhagen, C. (forthcoming). The mundane experience of everyday calorie trackers: Beyond the metaphor of Quantified Self. Forthcoming in New Media \& Society. 
Though in Georgina's case health referred to a specific medical issue, for many participants who mentioned both health and appearance as motivators, health meant being generally more active and energetic, as well as living a longer, more productive life. This was sometimes associated with children, as stated by Audrey, a financial advisor and a selfconfessed lifetime dieter in her forties: 'you've got kids you want to stay around for years, you don't want to pass out and die when you're 50.' Four participants had looked up their respective body mass index (BMI) and geared their weight loss towards it. One of them, Emily, a teacher and a mum of two toddlers, was aiming to lose her 'baby weight' and 'wanted to lose two stone [12.7 kilograms], because again on the internet, the wonderful thing, it said that [the weight was] like a good BMI, middle kind of BMI for my age and height.'

Some participants wanted to lose weight because of a specific health concern. Judy, a fortyseven-year-old manager, was diagnosed with high blood pressure and her doctor told her to either lose weight or go on medications. She successfully achieved her goals - losing weight and lowering her blood pressure - partly thanks to MyFitnessPal, recommended by a colleague, a sports scientist:

Well, I was diagnosed with high blood pressure back in 2013, and I didn't want to go on medication [...] Because the doctor said 16 pounds $[7.25$ kilograms], exercising 2 to 3 times a week or I'm gonna put you on medication. At this point, I was 45 years old. [...] Contacted sports science of everyday calorie trackers: Beyond the metaphor of Quantified Self. Forthcoming in New Media \& Society. 
colleague, and he starts working with me $[\ldots]$ And at that point he said to me - have you come across MyFitnessPal, erm, I use it, friends use it, give it a go.

Thus, our participants self-tracked to lose weight, to look better and sometimes to improve their health. Even though these goals were associated with self-improvement, they were rather modest, and often not particularly novel, in comparison to the quest to 'optimise' diverse aspects of one's life as depicted by the QS metaphor. In short, our participants' goals were more specific, temporary, modest and mundane than the expansive, continuous, and novel goals encompassed by the metaphor of QS in the literature.

\section{Ordinary use}

\section{Trust in data and device}

When getting started with MyFitnessPal, users need to enter their weight and height, their activity level and their weight goal. They also need to state how much they want to lose per week. The app then provides daily calorie and nutrient goals. Although MyFitnessPal allows users to customise these goals by entering their own calorie/nutrient limits, our participants usually followed the calorie and nutrient limit offered by the technology. Similar to self-trackers in the studies by Niva (2015) and Ruckenstein (2014), our participants simply thought that this was the way to use it. This is illustrated by Emily, who when asked why she decided that 1400 calories were the right limit, explained 'Because that's what it tells me.'

Didžiokaite, G., Saukko, P., \& Greiffenhagen, C. (forthcoming). The mundane experience of everyday calorie trackers: Beyond the metaphor of Quantified Self. Forthcoming in New Media \& Society. 
Most participants who simply wanted to lose weight, like Lilian, a 35-year-old school administrator, who lost four 26 kilograms using the app and made friends on its forum, trusted the app and its creators. Lilian described them as 'the experts because they are the ones that formulated the numbers.' Similarly, Dom, a 40-year-old teacher, who lost around 38 kilograms using MyFitnessPal, explained:

[1] was all app-driven, I made no personal decisions to change, and I figure, you know, basically I've put the trust in the app, I kind of decided that the people who made it know much more about health and kind of like diet then I do, if they're telling me then you know. And it's got thousands and thousands of users, hundreds and hundreds of thousands of users, so you know.

Some participants tinkered with the calorie/nutrient limits. These were usually either personal trainers (who would suggest to their clients how many calories they should consume based on their own calculations) or the more physically active weight loss pursuers. However, participants did not find the adjustment of the nutrient goal straightforward. As Freddie, a gym manager and ardent bodybuilder, who used MyFitnessPal to get leaner before his annual photo shoot, recounted:

When it was making my goals it was making my protein too low, and I knew it was too low. But I didn't know where to go with it, because I didn't know enough about it and I kind of got a bit frustrated.

Didžiokaite, G., Saukko, P., \& Greiffenhagen, C. (forthcoming). The mundane experience of everyday calorie trackers: Beyond the metaphor of Quantified Self. Forthcoming in New Media \& Society. 
Thus for many of our participants, the app was treated as an authoritative tool, providing them with a figure of how many calories they should be eating to achieve their weight goal. Participants did not question these numerical targets and did not look for an alternative, maybe more personalised, number. The QS metaphor speaks of how self-trackers 'use their bodies and the cultural resources around them to see outside the frame that devices set for them' (Nafus and Sherman, 2014: 1793) and aim to find personally useful measurements (Neff and Nafus, 2015; Sharon and Zandbergen, 2016). In contrast, our participants expected the app to provide them with a straightforward calorie/nutrient limit to help them lose weight. Whilst few of them were aware that individual calorie needs were dependent on the body's metabolism, they did not seek to personalise the calorie limit.

\section{Basic use}

In contrast with other self-tracking tools or apps, which automatically log the data (e.g., how many steps you have taken), MyFitnessPal requires users to manually log the items they eat and drink. Nevertheless, MyFitnessPal offers various features to help with this process: there is a large database from which participants can select items (if items are not already in the database, participants must manually enter information). There is also the possibility to use a barcode scanner to read the calories from packaged foods.

Generally, participants found MyFitnessPal easy to use. Alex, an undergraduate student in his late twenties, said that 'it was easy and understandable, easy to sort of pick up, yeah everything is pretty self-explanatory really,' reflecting the general tone of evaluations.

Didžiokaite, G., Saukko, P., \& Greiffenhagen, C. (forthcoming). The mundane experience of everyday calorie trackers: Beyond the metaphor of Quantified Self. Forthcoming in New Media \& Society. 
However, finding the app easy did not mean that participants were familiar with, or keen to use all its features. Participants usually were like Ruth, a 31-year-old lecturer and sporadic MyFitnessPal user, who 'didn't even realise [recipe importing from the internet] was up there,' though when told about the function thought it was 'amazing.' The barcode scanner was praised by some participants as the quickest and most precise way of logging food in MyFitnessPal. Others did not know about it. One of them, Audrey, who 'had [the app] for ages' and was always searching for foods in the database - the first option that app displays - was surprised when asked if she used the scanner: 'I wasn't aware of that, is it like a barcode scanner on your phone?'. Another participant, Freddie, also confessed that until his friend showed the barcode scanner to him, he did not know that there was one, although he had been using the app for a long time:

because it doesn't really tell you in the app that it's got that, it's just the tiny little icon of the barcode at the top and you're like, if $[\ldots]$ you're new to the app, unless you sit and go through all different icons at the bottom, you go - oh, hang on a minute.

While Freddie and Audrey were not using the barcode scanner because they did not know about it, others did not use it because it required too much skill to master. Eve, a nurse advisor in her fifties, was recommended the app by her colleague, who used to scan food in the common room at work, and explained:

Q: But you said you didn't use the scanner? Or did you?

Didžiokaite, G., Saukko, P., \& Greiffenhagen, C. (forthcoming). The mundane experience of everyday calorie trackers: Beyond the metaphor of Quantified Self. Forthcoming in New Media \& Society. 
Eve: No, I wasn't, no I didn't use the scanner to scan food, the packing. I wasn't quite sure how you did that, so.

Q: But you knew there was a scanner, because your manager...

Eve: He told me about that, I think he used to get a bit frustrated with it. The thing is when I retire I'm gonna go to a computer course, a bit later.

A similar apologetic tone about technological competence is echoed by Judy:

I input manually, yeah. I'm not technically particularly brilliant, to be honest. So I've always, erm, everytime I have a meal, erm, I go into the app and erm so I go to my diary and I input.

Instead of trying to figure out how to manage the barcode scanner and make their food logging quicker, Eve and Judy continued to log food manually, searching the database. For them learning to use the barcode scanner was seen to require more effort than the daily manual input.

Our participants' stories reveal that they often used the technology in a basic way, sometimes not knowing about, or struggling with, more advanced features. This is in line with other studies, which have shown how older adults struggle with using selfmonitoring technologies and want more instructions (Mercer et al., 2016). Our study illustrates that also early mid-lifers, who have chosen to self-track, may find the devices complicated and end up using them in a basic way. This confirms findings in human-

Didžiokaite, G., Saukko, P., \& Greiffenhagen, C. (forthcoming). The mundane experience of everyday calorie trackers: Beyond the metaphor of Quantified Self. Forthcoming in New Media \& Society. 
computer interaction (HCI) that people rarely know all features of even the most common technologies, such as software (McGrenere and Moore, 2000) or household appliances (Blackler et al., 2016). However, this use of technologies stands in contrast to the image of self-tracking drawn by the QS metaphor, where self-trackers are enthusiastic about the possibilities of technologies and keen to adapt or modify them to fit their needs (Choe et al., 2014; Lee, 2014). The everyday calorie trackers we interviewed appreciated simple, easy to use technology. Rather than modifying the technology and to explore its more advanced features, they stuck to the basic features and trusted the information provided.

\section{Prospective tracking}

Self-tracking tools usually provide users with information or data on what they did in the past day, week, month, or even year. The possibility of using these data to retrospectively track trends in one's life has attracted attention in the literature on self-tracking. Our participants, however, rarely engaged in 'looking back.'

MyFitnessPal provides ample opportunity for observing your progress through time. Users could check how their weight had changed or how well they kept to the calorie and nutrient goals throughout the day or within a week. Some users found the historical logs motivating, especially during times when the weight loss was not going according to the plan. For example, Serge, who became enthusiastic about nutrition and sports during his MyFitnessPal use, said:

Didžiokaite, G., Saukko, P., \& Greiffenhagen, C. (forthcoming). The mundane experience of everyday calorie trackers: Beyond the metaphor of Quantified Self. Forthcoming in New Media \& Society. 
I think I used the, to stay motivated to plan, I used the graphs of your weight-loss over time and just saw how that graph was always going down, so on the occasional week when it gone up, I'd go - ok, well it's gone up this week that's fine, I just need to get back on it.

But overall the graphs were rarely looked at and not valued. Some participants, like Wilma, a police officer in her forties who wanted to lose weight to be able to fit into her older clothes, saw no point in looking back:

I don't look back, but I know that I had two bad days, you know, I don't scroll through it and go oh, I had you know, 3000 over, I don't look back but in my mind, I know that on two days I probably been really bad.

Other participants were more concentrated on the app's estimation of the weight in the future, i.e., in a few weeks' time. For example, Vijay, a postgraduate student who learned by using MyFitnessPal that eating biscuits interfered with his weight loss, stated:

Oh no, I don't look at [historical data], most I look when it says at the end of the day to complete the entry, that's the one I click because it gives you what you would be in the next four weeks [...] It makes me feel good, it's just about it.

The QS metaphor suggests an image of self-trackers as engaging in 'long-term reflection' through data (Li et al., 2010): looking and analysing the accumulated data, aiming to spot of everyday calorie trackers: Beyond the metaphor of Quantified Self. Forthcoming in New Media \& Society. 
trends or correlations and finding explanations for behaviours or changes. When asked to look at the extracts of food diaries our participants often did engage in 'data-work' (Elsden et al., 2015), i.e., they explained their food choices and described the background for their choices. However, as the quotes show, looking back at their past data was not something they normally did. It seems that the past for the participants was more a point of departure, something to get away from, rather than something to be looked at and analysed (especially in cases such as Wilma, when participants knew that they had 'been really bad'). It was the future, and the anticipated changes, that participants focused on. This prospective rather than retrospective attitude is similar to the findings of Rooksby et al. (2014: 1171), who argued that ' $[\mathrm{t}]$ racking is often about where you are heading in life.'

\section{Ordinary effect}

As hinted in the previous section, self-tracking technologies offer the opportunity - and for some, the hope - of changes in behaviour, possibly helping to lead healthier lives. Talking to our participants it became clear that using MFP did lead to some changes in both their behaviour and awareness. However, again, these changes were rather modest and often temporary. They mainly related to perceiving food items differently, but did not involve any fundamental and continuous changes, or form the basis of the creation of a new self, as suggested in the QS metaphor on self-tracking.

Through notifications about nutrients and its blog MyFitnessPal aspires to 'nudge' users to make 'healthier' decisions about food. But because participants mainly wanted to lose of everyday calorie trackers: Beyond the metaphor of Quantified Self. Forthcoming in New Media \& Society. 
weight, they typically used MyFitnessPal only as a calorie counter. Therefore, the changes inspired by MyFitnessPal had to do with participants' perception of food, in particular, making them think about food items in terms of calories. This new way of looking at food was sometimes surprising and revelatory, like when Eve found how calorific chocolates were:

Yeah, it makes you realise how many calories there are in [sweets] ... [s]omebody had brought some Celebrations, and I think 6 celebrations will add up to 300-400 calories. I had no idea, that sort of these little chocolates could be so much. I was - oh my god!

Being surprised by the data collected by self-tracking has been documented in other studies as well (Ruckenstein, 2014), and it shows that the use of MyFitnessPal did change the perception and awareness of our participants. The need to track food and count calories made participants, in Audrey's words, 'really really mindful of what you're eating during the day, rather than just eating whatever sort of goes past you.' Another participant, Dom, noted that the need to log your food made you see how the calories of a chosen food can add to the daily calorie count. For Dom, this constituted 'a breakpoint $[. .$.$] a point between$ you and eating.'

This new awareness made some participants rethink their choices. As Lilian explained, after a while these changes became 'internalised', i.e., participants remembered 'which foods are the best ones to eat and which ones are your treat foods really.' So similarly to photo-based of everyday calorie trackers: Beyond the metaphor of Quantified Self. Forthcoming in New Media \& Society. 
food journalers (Cordeiro, Bales, et al., 2015), participants not only learned to re-evaluate the foods based on their caloric and nutritional value but also became generally more aware of what they were eating. This confirms the health research argument that self-monitoring helps people become more aware of the practice that is being monitored (Wilde and Garvin, 2007).

However, when asked whether using MyFitnessPal had an effect on what they thought about themselves, participants either disagreed or only talked about their changed perception of food. This is illustrated by Amy, a project officer and avid gym goer in her thirties, who only found MyFitnessPal as a source of information about food:

Amy: No. I don’t think it has changed the way I think about myself. Well, maybe, I know I'm doing the right thing, and I know I have a lot of knowledge, that it's already provided me with.

Thus, while the use of MyFitnessPal resulted in new knowledge about calorie values of foods, it did not entail (better) knowledge of the self as the QS metaphor implies (Nafus and Sherman, 2014; Ruckenstein and Pantzar, 2015). Our everyday calorie trackers learned about calories, but did not engage in the creation of a new self (Lupton, 2013a, 2013b; Swan, 2013).

The QS metaphor depicts self-tracking as a life-long activity, a lifestyle (Choe et al., 2014; Schüll, 2016). However, for many everyday calorie trackers, MyFitnessPal was simply a tool of everyday calorie trackers: Beyond the metaphor of Quantified Self. Forthcoming in New Media \& Society. 
to be used over a short period. As Justine explained, for her MyFitnessPal was 'a tool that helps me if I need a change, if I need to lose a bit of weight, I know that there's a tool that I can turn to.' In other words, our everyday calorie trackers usually engaged in self-tracking sporadically, when they felt unhappy about their weight. Many of them did lose some weight as planned. As a consequence, they would often stop using MyFitnessPal and therefore regain their weight, which in turn prompted them to return to use MyFitnessPal again. The reason for gaining weight, after stopping to use MyFitnessPal, was not that our participants forgot what they learned about food using MyFitnessPal, but because they stopped controlling their diet. This is illustrated by Joe, an IT technician in his late forties, who aimed to lose weight and build muscle:

I was made aware of what I was actually eating, I was able to maintain, you know that diet. [...] But when you're not using the app, it's a lot easier to start eating stuff that has quite high calorific content.

Thus, for our everyday calorie counters, self-tracking did not become a new way of living. The effects of using MyFitnessPal were limited both in its scope (influenced some of the food choices and helped to lose some weight) and duration (influence was connected to the continuous use of the app). These limited and temporary effects offer a counter-point to the expansive effects in terms of changing one's self and future on a long-term basis, characteristic of the picture drawn by the metaphor of QS in the literature.

Didžiokaite, G., Saukko, P., \& Greiffenhagen, C. (forthcoming). The mundane experience of everyday calorie trackers: Beyond the metaphor of Quantified Self. Forthcoming in New Media \& Society. 


\section{Conclusion}

Ruckenstein and Panztar suggested that the QS metaphor should not define selfquantification, but be a point of departure for a further examination of actual practices, noting that 'epistemological claims advanced as formative for the data-driven paradigm should be rethought as epistemological inquiries' (2015: 12). In this article, we have followed their suggestion as well as earlier research on Internet and health (Henwood et al., 2003; Nettleton et al., 2005; Wyatt, 2003) and have deliberately attended to the experiences of ordinary or everyday users, who may engage with the technology in a way that does not conform to hype. The shift is necessary because, as our study showed, the focus only on those actively engaging with new technologies skews the vision of the technology, its use and users, and fosters unwarranted expectations and visions.

Metaphors not only help us to talk about technology, but as Wyatt (2004: 257) notes, metaphors form visions and perceptions of technology and can 'shape the future.' Ruckenstein and Pantzar (2015) note how the QS metaphor in Wired partakes in the generation of a data-driven technology market. The components of the metaphor illustrate the contradictory features of the Californian or Silicon Valley high tech discourse, professed by Wired, combining elements of sixties counterculture and hardened entrepreneurialism (Barbrook and Cameron, 1996). So, the idea of continuous optimisation of one's self and performance harks back to individualistic entrepreneurialism

Didžiokaite, G., Saukko, P., \& Greiffenhagen, C. (forthcoming). The mundane experience of everyday calorie trackers: Beyond the metaphor of Quantified Self. Forthcoming in New Media \& Society. 
and the notion of biohacking to the romantic ideas of hackers as emblematic of countercultural sharing and creativity, as articulated by, for example, Himanen (2001).

In contrast with the QS metaphor's portrayal of self-tracking as imaginative biohacking, our everyday calorie trackers used the app at a basic level and were keen to trust and be guided by the data and information provided by it. The QS metaphor also emphasises long-term changes, such as self-tracking adding to self-knowledge and continuous enhancement of health and performance. In contrast, the changes induced by MyFitnessPal to our everyday calorie trackers were targeted and had limited scope and duration. Everyday calorie trackers can be seen as less active in their tracking than QS trackers, but they are also less self-disciplining as they focus solely on tracking calories here and now. Hence, we suggest that the features of self-tracking's image as indicated by the QS metaphor are exaggerated when compared to real-life self-tracking practices, both in the positive sense of creative use and in the negative sense of relentless disciplining or optimising all areas of life.

Based on our findings, we argue that a new picture of self-tracking emerges. Instead of the image of individuals actively transforming and personalising technologies (as portrayed by the QS metaphor), we see individuals using a new technology in a rather limited and less enthusiastic manner. Secondly, rather than self-tracking resulting in a fundamental change in terms of how people see themselves, leading to the creation of a new self, for our everyday calorie trackers, the use of MyFitnessPal resulted in temporary and very specific incremental of everyday calorie trackers: Beyond the metaphor of Quantified Self. Forthcoming in New Media \& Society. 
change. None of this is to deny that self-tracking does not affect the way we perceive and take care of our lives. Ultimately it continues the trends of quantification (Porter, 1995) and promotion of self-care. However, our findings suggest that these trends are likely to be less expansive and profound in the everyday use of self-tracking technologies than indicated by the QS metaphor.

\section{Acknowledgements}

We want to thank our participants. This research was partly funded by a $\mathrm{PhD}$ studentship awarded to the first author by the School of Social, Political and Geographical Sciences, Loughborough University, UK.

Didžiokaite, G., Saukko, P., \& Greiffenhagen, C. (forthcoming). The mundane experience of everyday calorie trackers: Beyond the metaphor of Quantified Self. Forthcoming in New Media \& Society. 


\section{References}

Bakardjieva M and Smith R (2001) The Internet in Everyday Life: Computer Networking from the Standpoint of the Domestic User. New Media \& Society 3(1): 67-83.

Barbrook R and Cameron A (1996) The Californian Ideology. Science as Culture 6(1): 44-72.

Blackler AL, Gomez R, Popovic V, et al. (2016) Life Is Too Short to RTFM: How Users Relate to Documentation and Excess Features in Consumer Products. Interacting with Computers 28(1): 27-46.

Cha AE (2015) The Revolution Will Be Digitized. The Washington Post. Available from: http://www.washingtonpost.com/sf/national/2015/05/09/the-revolution-will-bedigitized/ (accessed 26 January 2016).

Charmaz KC (2006) Constructing Grounded Theory: A Practical Guide through Qualitative Analysis. 1st ed. London, Thousand Oaks, New Delhi,: Sage Publications.

Choe EK, Lee NB, Lee B, et al. (2014) Understanding Quantified-selfers' Practices in Collecting and Exploring Personal Data. Proceedings of the 32 nd annual ACM conference on Human factors in computing systems, New York, New York, USA: ACM Press: 11431152.

Cohen I and Blavin J (2002) Gore, Gibson, and Goldsmith: The evolution of Internet metaphors in law and commentary. Harvard Journal of Law and Technology 16(1): 265.

Didžiokaite, G., Saukko, P., \& Greiffenhagen, C. (forthcoming). The mundane experience of everyday calorie trackers: Beyond the metaphor of Quantified Self. Forthcoming in New Media \& Society. 
Cordeiro F, Epstein DA, Thomaz E, et al. (2015) Barriers and Negative Nudges: Exploring Challenges in Food Journaling. In: Proceedings of the 33rd Annual ACM Conference on Human Factors in Computing Systems, ACM, pp. 1159-1162.

Cordeiro F, Bales E, Cherry E, et al. (2015) Rethinking the Mobile Food Journal: Exploring Opportunities for Lightweight Photo-Based Capture. In: Proceedings of the 33rd Annual ACM Conference on Human Factors in Computing Systems, ACM, pp. 32073216.

De Certeau M (1984) The Practice of Everyday Life. Berkley, CA: University of California Press.

Denzin NK (1978) The research act: A theoretical introduction to research methods. New York: McGraw-Hill.

Elsden C, Kirk DS and Durrant AC (2015) A Quantified Past: Towards Design for Remembering with Personal Informatics. Human-Computer Interaction: 1-40.

Glaser AL and Strauss BG (1967) The Discovery of Grounded Theory: Strategies for Qualitative Research. New York: Aldine de Gruyter.

Hellsten I (2003) Focus On Metaphors: The Case Of 'Frankenfood' On The Web. Journal of Computer-Mediated Communication 8(4).

Henwood F, Wyatt S, Hart A, et al. (2003) 'Ignorance Is Bliss Sometimes': Constraints On

Didžiokaite, G., Saukko, P., \& Greiffenhagen, C. (forthcoming). The mundane experience of everyday calorie trackers: Beyond the metaphor of Quantified Self. Forthcoming in New Media \& Society. 
the Emergence Of the 'Informed Patient' In the Changing Landscapes Of Health Information. Sociology of Health and Illness 25(6): 589-607.

Himanen P (2001) The Hacker Ethic and the Spirit of Capitalism. New York: Random House.

Lakoff G and Johnson M (1980) Metaphors we live by. Chicago, IL: Chicago University Press.

Lee VR (2014) What's Happening in the 'Quantified Self Movement? In: ICLS 2014 Proceedings, pp. 1032-1036.

Li I, Dey A and Forlizzi J (2010) A Stage-based Model of Personal Informatics Systems. In: Proceedings of the SIGCHI 2010, ACM, pp. 557-566.

Lupton D (2013a) Quantifying the Body: Monitoring and Measuring Health in the Age of mHealth Technologies. Critical Public Health 23(4): 393-403.

Lupton D (2013b) Understanding the Human Machine. IEEE Technology and Society Magazine 32(4): 25-30.

Lupton D (2016) The Quantified Self: a Sociology of Self-tracking. Malden, MA: Polity Press.

McGrenere J and Moore G (2000) Are We All In the Same 'Bloat'? Graphics Interface 2000 (May): 187-196.

Mercer K, Giangregorio L, Schneider E, et al. (2016) Acceptance of Commercially Available Wearable Activity Trackers Among Adults Aged Over 50 and With Chronic Illness: A Mixed-Methods Evaluation. JMIR mHealth and uHealth 4(1): e7.

Didžiokaite, G., Saukko, P., \& Greiffenhagen, C. (forthcoming). The mundane experience of everyday calorie trackers: Beyond the metaphor of Quantified Self. Forthcoming in New Media \& Society. 
Nafus D and Sherman J (2014) This One Does Not Go Up to 11: The Quantified Self Movement as an Alternative Big Data Practice. International Journal of Communications 8: 1784-1794.

Neff G and Nafus D (2015) Self-tracking. Cambridge, MA: MIT Press.

Nettleton S, Burrows R and O'Malley L (2005) The Mundane Realities of the Everyday Lay Use of the Internet For Health, and Their Consequences For Media Convergence. Sociology of Health and Illness 27(7): 972-992.

Niva M (2015) Online Weight-loss Services and a Calculative Practice of Slimming. Health: An Interdisciplinary Journal for the Social Study of Health, Illness and Medicine.

Porter TM (1995) Trust in Numbers. The Pursuit of Objectivity In Science and Public Life. Princeton: Princeton University Press.

Rooksby J, Rost M, Morrison A, et al. (2014) Personal Tracking As Lived Informatics. In: Proceedings of the SIGCHI Conference on Human Factors in Computing Systems, ACM Press, pp. 1163-1172.

Ruckenstein M (2014) Visualized and Interacted Life: Personal Analytics and Engagements with Data Doubles. Societies 4(1): 68-84.

Ruckenstein M (2015) Uncovering Everyday Rhythms and Patterns: Food Tracking and New Forms of Visibility and Temporality in Health Care. In: Botin; L, Pernille B, and

Didžiokaite, G., Saukko, P., \& Greiffenhagen, C. (forthcoming). The mundane experience of everyday calorie trackers: Beyond the metaphor of Quantified Self. Forthcoming in New Media \& Society. 
Nøhr C (eds), Techno-Anthropology in Health Informatics: Methodologies for Improving HumanTechnology Relations, pp. 28-40.

Ruckenstein M and Pantzar M (2015) Beyond the Quantified Self: Thematic exploration of a dataistic paradigm. New Media \& Society: 1-18.

Schüll ND (2016) Data For life: Wearable Technology and The Design Of Self-care. BioSocieties: 1-17.

Schutz A and Luckmann T (1973) The structures of the life-world [by] Alfred Schutz and Thomas Luckmann. Translated by Richard M. Zaner and H. Tristram Engelhardt, Jr. Northwestern University Press.

Sharon T and Zandbergen D (2016) From Data Fetishism To Quantifying Selves: Selftracking Practices and the Other Values Of Data. New Media \& Society: 1-15.

Statista (2015) Unit Shipments Forecast Basic/Smart Wearables Worldwide From 2014 to 2019 (in millions). Available from: http://www.statista.com/statistics/296565/wearables-worldwide-shipments/ (accessed 5 October 2015).

Swan M (2012) Health 2050: The Realization of Personalized Medicine through Crowdsourcing, the Quantified Self, and the Participatory Biocitizen. Journal of personalized medicine 2(3): 93-118.

Didžiokaite, G., Saukko, P., \& Greiffenhagen, C. (forthcoming). The mundane experience of everyday calorie trackers: Beyond the metaphor of Quantified Self. Forthcoming in New Media \& Society. 
Swan M (2013) The Quantified Self: Fundamental Disruption in Big Data Science and Biological Discovery. Big Data 1(2): 85-99.

Weintraub K (2013) Quantified Self: the Tech Based Route to Better Self. BBC Future. Available from: http://www.bbc.com/future/story/20130102-self-track-route-to-abetter-life (accessed 3 January 2016).

Whooley M, Ploderer B and Gray K (2014) On the Integration of Self-tracking Data amongst Quantified Self Members. In: Proceedings of the 28th International BCS Human Computer Interaction Conference, pp. 151-160.

Wilde MH and Garvin S (2007) A Concept Analysis of Self-Monitoring. Journal of Advanced Nursing 57(3): 339-350.

Wolf G (2010) The Data-Driven Life. The New York Times, 2nd May. Available from: http://www.nytimes.com/2010/05/02/magazine/02self-measurement-t.html.

Wyatt S (2003) Non-users Also Matter. The Construction of Users and Non-users Of the Internet. In: Oudshoorn N and Pinch T (eds), How users matter. The co-construction of users and technologies, Cambridge, MA: MIT Press, pp. 67-80.

Wyatt S (2004) Danger! Metaphors at Work in Economics, Geophysiology, and the Internet. Science, Technology, \& Human Values 29(2): 242-261.

Didžiokaite, G., Saukko, P., \& Greiffenhagen, C. (forthcoming). The mundane experience of everyday calorie trackers: Beyond the metaphor of Quantified Self. Forthcoming in New Media \& Society. 
Didžiokaite, G., Saukko, P., \& Greiffenhagen, C. (forthcoming). The mundane experience of everyday calorie trackers: Beyond the metaphor of Quantified Self. Forthcoming in New Media \& Society. 
Gabija Didžiokaitè - corresponding author g.didziokaite@lboro.ac.uk

Gabija Didžiokaite (MSc (Research) in Social Sciences, specialising in Medical Anthropology, from University of Amsterdam) is a $\mathrm{PhD}$ candidate at Loughborough University Social Sciences Department. Her current work looks at practices of self-tracking, more specifically at use of calorie counting and diet tracking app MyFitnessPal.

\section{Paula M. Saukko}

Paula Saukko (PhD, University of Illinois at Urbana-Champaign, USA) is a Reader in Social Science and Medicine at the Department of Social Sciences, Loughborough University, UK. Her work is located between Medical Sociology, Science and Technology Studies and Communication and focuses on new medical/diagnostic technologies, digital media and qualitative methodology.

\section{Christian Greiffenhagen}

Christian Greiffenhagen (DPhil, University of Oxford) is Assistant Professor in Sociology at the Department of Sociology at The Chinese University of Hong Kong (CUHK) and Senior Lecturer at Loughborough University. He is working in the areas of Science \& Technology Studies (STS) and Human-Computer Interaction (HCI), where he uses ethnomethodology and conversation analysis to study scientific work and new technologies 'in use'.

Didžiokaite, G., Saukko, P., \& Greiffenhagen, C. (forthcoming). The mundane experience of everyday calorie trackers: Beyond the metaphor of Quantified Self. Forthcoming in New Media \& Society. 